\title{
Responding to common questions on the conservation of agricultural heritage systems in China
}

\author{
MIN Qingwen ${ }^{1}$, ZHANG Yongxun ${ }^{1,2}$, "JIAO Wenjun ${ }^{1}$, SUN Xueping ${ }^{1,2}$ \\ 1. Institute of Geographic Sciences and Natural Resources Research, CAS, Beijing 100101, China; \\ 2. University of Chinese Academy of Sciences, Beijing 100049, China
}

\begin{abstract}
Although the urgency of their conservation has been recognized, Globally Important Agricultural Heritage Systems (GIAHS) designated by the Food and Agriculture Organization (FAO) since 2002 and China Nationally Important Agricultural Heritage Systems (ChinaNIAHS) certified by the Ministry of Agriculture (MOA) of China since 2012 are faced with questions as to why to conserve them, what is to be conserved, who should conserve them, and how? This paper attempts to clarify and respond to such questions focusing on the conservation of agricultural heritage systems in China based on a review of both theoretical and practical progress. Agricultural heritage systems exhibit a multitude of values for sustainable and equitable development and therefore should be conserved for both present and future generations. Unlike most conventional heritages, the conservation of agricultural heritage systems is a complex, systematic "engineering" in which both physical and biological components and associated socio-cultural processes should be conserved in a dynamic way. Farmers and heritage sites must benefit from the continuance of traditional agricultural production under the premise of ecological functions being sustained and traditional culture being inherited. For a more effective conservation, a multi- stakeholder process should be established involving governments at different levels, multi-disciplinary scientists, communities and farmers, and business enterprises as well as social organizations. As has been demonstrated, the conservation of agricultural heritage systems aims to promote the regional sustainable development, to improve the livelihood, food security and well-being of farm people, and to provide references for the development of modern agriculture in China.
\end{abstract}

Keywords: Globally Important Agricultural Heritage Systems (GIAHS); China Nationally Important Agricultural Heritage Systems (China-NIAHS); dynamic conservation; sustainable development; China

\section{Introduction}

Agricultural heritage systems refer to those farming systems with heritage values, including the Globally Important Agricultural Heritage Systems (GIAHS) designated by the Food and

Received: 2016-03-21 Accepted: 2016-04-05

Foundation: Youth Talent Supporting Project of China Association for Science and Technology, No.2016010103; International Exchange and Cooperation Project of Ministry of Agriculture "Conservation of Globally Important Agricultural Heritage Systems (GIAHS) in China in 2016"; Scientific Research Foundation for Youth Scholars of Institute of Geographic Sciences and Natural Resources Research, Chinese Academy of Sciences

Author: Min Qingwen (1963-), Professor, specialized in agricultural heritage systems conservation and regional sustainable development. E-mail: minqw@igsnrr.ac.cn

*Corresponding author: Jiao Wenjun (1983-), Assistant Professor, E-mail: jiaowj@igsnrr.ac.cn 
Agriculture Organization (FAO) of the United Nations and the China Nationally Important Agricultural Heritage Systems (China-NIAHS) certified by the Ministry of Agriculture (MOA) of China. Compared with conventional heritages like natural, cultural, mixed and intangible cultural heritages launched by United Nations Educational, Scientific and Cultural Organization (UNESCO), the concept of GIAHS/NIAHS is quite new to the world, but it has been increasingly recognized by the international community in recent years.

In response to the global trends that undermine small-scale family agriculture and traditional agricultural systems, FAO started a global partnership initiative on the conservation and adaptive management of GIAHS during the World Summit on Sustainable Development in 2002 (Koohafkan and dela Cruz, 2011). At that time, five traditional agricultural systems located in six countries were designated as the first pilot systems in 2005. These are Rice-Fish Culture in China, Andean Agriculture in Peru, Chiloe Agriculture in Chile, Ifugao Rice Terraces in the Philippines and the Oases agriculture of the Maghreb in Algeria and Tunisia (Koohafkan, 2009). With support from international organizations like the United Nations Development Programme (UNDP), UNESCO, International Fund for Agriculture Development (IFAD) and the United Nations University (UNU), the GIAHS project was approved by the Council of Global Environment Facility (GEF) in 2008 and was officially started across the world in 2009 (Min et al., 2010). After the 5-year-long implementation phase, progress on the dynamic conservation and adaptive management of GIAHS has been widely achieved and the influence of the GIAHS initiative has been greatly expanded. In June, 2015, the GIAHS initiative was endorsed as a corporate programme at the FAO 39th Session, ushering in a whole new stage for the conservation and management of GIAHS globally.

China is one of the first countries that responded to the GIAHS initiative, witnessed by the designation of Rice-Fish Culture in June, 2005 (Altieri and Koohafkan, 2007; Min et al., 2009b). The start-up meeting for the conservation and adaptive management of GIAHSChina Rice-Fish Culture was held in Beijing in February, 2009, which marked the GIAHS project start-up in China (Min et al., 2010). In March, 2012, MOA initiated the identification and conservation of China-NIAHS, which enabled China to become the first country in the world to select and conserve agricultural heritage systems at the national level. Both the China - GIAHS Scientific Committee and the China-NIAHS Scientific Committee were established in 2014, being responsible for the recommendation of GIAHS and NIAHS candidates to MOA as well as the improvement of the scientific rationality of their conservation and management. More importantly, the Ministry issued and implemented the Procedures on the Administration of Important Agricultural Heritage Systems ${ }^{1}$ in August, 2015, which was the first legal document on the administration of agricultural heritage systems in the world. By the end of 2015, the number of GIAHS designations in China had reached 11 (Appendix 1), accounting for about one third of the total allotment (that was 36) in the world. The total number of China-NIAHS came to 62 by the end of 2015 (Appendix 1), distributed in 25 provinces, municipalities and autonomous regions in the mainland of China.

Thanks to a top-down effort to promote the initiative, GIAHS/China-NIAHS has become a nationwide concept in China. Although the development process has been relatively short, the urgency of GIAHS/China-NIAHS conservation has been recognized widely, as many of

${ }^{1}$ http://www.moa.gov.cn/sjzz/zhengfasi/fagui/201509/t20150907_4818823.htm [accessed on 15 March, 2016] 
them have been increasingly challenged by industrialization and urbanization (Min et al., 2009a). However, for an effective conservation of agricultural heritage systems, at least four questions are most often discussed and must be considered first. They are: why should agricultural heritage systems be conserved? what should be conserved? how should they be conserved? and, who should conserve them? This paper aims to help clarify the discussion surrounding the conservation of agricultural heritage systems by providing detailed responses to the four common questions about GIAHS/NIAHS in China.

\section{Why should agricultural heritage systems be conserved?}

The reason why agricultural heritage systems should be conserved can be easily explained when their values are fully and accurately recognized. Similar to cultural and natural heritages, agricultural heritage systems also have "outstanding universal values (OUV)". However, their OUV have their own connotations embedded in ecological and environmental advantages, social and cultural merits, including economy and livelihood, research and education, demonstration and promotion (Min et al., 2012).

One of the ecological advantages of agricultural heritage systems lies in that they have important genetic resources and are rich in agricultural biodiversity. Many research studies have demonstrated this. Different kinds of local varieties have been formed in the co-adaptation of the local community with its environment and have been well preserved in the agricultural heritage systems (Zhang et al., 2014b; Xia and Shen, 2014), which are richer in genetic diversity (Xia and Shen, 2014; Duan et al., 2004) and more adaptive to a changing environment (He et al., 2011; Lei et al., 2013) compared to new varieties in modern conventional agriculture. Another ecological advantage of agricultural heritage systems refers to the provision of important ecosystem services, such as water and soil conservation (Zhang et al., 2014b; Zong et al., 2014), control of diseases, pests and weeds (Zhu et al., 2000; Xie et al., 2011a; Xie et al., 2009; Zhang et al., 2011a; Zhang et al., 2011b), resilience to extreme climate (Sun et al., 2012; Bai et al., 2013; Sun et al., 2014), micro-climate regulation (Ren et al., 2014), improvement in soil fertility (Xie et al., 2011a; Zhang et al., 2014a) and resources utilization (Yang et al., 2009), reduction in non-point pollution (Xie et al., 2011b) and greenhouse gas emission (Ren et al., 2008), and maintenance of regional ecological balance (Jiao et al., 2009; Jiao et al., 2011).

The diversified biological resources and production processes in agricultural heritage systems bring about an abundance of agricultural products for local communities (He et al., 2010; Li et al., 2012; Zhu et al., 2015), including grains, vegetables, fruits, meat, oil, timber, fuel, medicine, dyes and sugar. The rich and varied products do not only provide local residents with adequate nutrition and food, but also improve their life quality by increasing their livelihood security, their health and social well-being. In addition, unique local varieties provide biological resources for the development of agriculture with local characteristics (Lei et al., 2013; Zhao et al., 2011; Xia and Shen, 2014); sound ecological conditions create a better environment for the development of ecological agriculture (Xie et al., 2011b); distinctive ethnic customs and local cultures promote the development of cultural (craft) industries and rural tourism (He et al., 2009; He et al., 2010). All of these help increase economic benefits and farmers' incomes from agricultural production, thus demonstrating widespread economic and livelihood values in agricultural heritage systems (Min et al., 2012; Berweck 
et al., 2013).

In terms of social values, agricultural heritage systems are able to engage a large number of labor force (Zhao et al., 2012), partly because their diversified production processes and management activities are both labor-intensive (Sun et al., 2008). Another reason rests with that the multi-functionality of such systems which greatly reduces the pressure brought about by surplus labor in rural areas (Liu et al., 2014). The cultural values of agricultural heritage systems are embodied in their farming culture and its related rules and regulations (Liu et al., 2011; Bai et al., 2013), religious rituals, customs and habits, traditional knowledge and adapted technologies (Rao et al., 2009; Xu et al., 2010; Xue, 2011; Jiao et al., 2012; Yuan et al., 2013; 2014), which are able to promote and sustain the harmony between humanity and the nature (Long, 2011). They are also represented in folk legends, songs and dances, diet, clothing and architectural culture related to agricultural activities, which act as an important medium to maintain cultural identity and promote cultural inheritance (He et al., 2010; Zhang et al., 2011c).

Agricultural heritage systems exhibit a multitude of values that are embodied in a variety of aspects and should be fully recognized by both administrators and farmers. These values did not matter in the past only, but are now important and will also play a role in the future: an important role in food security, food safety, the growth of economy, the maintenance of social stability and the inheritance of traditional culture at both the local and national levels, which is exactly the reason why agricultural heritage systems should be conserved.

\section{What should be conserved?}

The answer to this question is closely related to the definition and connotation of agricultural heritage systems as well as their component parts.

Defined by FAO in 2002, GIAHS are "remarkable land use systems and landscapes which are rich in globally significant biological biodiversity evolving from the co-adaptation of a community with its environment and its needs and aspirations for sustainable development" (Koohafkan, 2009). On the basis of this definition, FAO has set corresponding criteria for the selection of GIAHS, requiring them to be of global importance with outstanding features. Global importance is a composite criterion, which synthesizes the overall global "public good" value described under the five subsequent criteria. The outstanding features are summarized in the five criteria that represent the totality of functions, goods and services provided by the system ${ }^{2}$. These criteria are food and livelihood security; biodiversity and ecosystem functions; knowledge systems and adapted technologies; culture, value systems and social organizations; remarkable landscapes, land and water resources management features (Koohafkan and dela Cruz, 2011).

China-NIAHS are defined by MOA in 2012 as "ingenious agricultural production systems created from the long-term co-adaptation of a rural community/population with its environment and inherited to now, that are rich in biological diversity, traditional knowledge and technologies, remarkable ecological and cultural landscape and are of important scientific and practical relevance to the inheritance, sustainability and multi-functionality of agriculture in China". The key features of China-NIAHS are described as living, adaptive, complex,

${ }^{2}$ http://www.fao.org/giahs/giahs/features-and-criteria/en/ [accessed on 15 March, 2016] 
strategic, multi-functional and endangered; the criteria for their selection are comprised of four basic measures and two supplementary ones (Table 1$)^{3}$.

Table 1 Comparison between GIAHS and China-NIAHS selection criteria

\begin{tabular}{ll}
\hline GIAHS selection criteria & China-NIAHS selection criteria \\
\hline - Food and livelihood security; & Basic measures \\
- Biodiversity and ecosystem function & - Historic relevance (origin, length of history) \\
- Knowledge system and adapted & - Completeness (materials and products, ecosystem services, \\
technology & knowledge and technological systems, landscape and aesthet- \\
- Culture, value system and social or- & ics, spirit and culture) \\
ganization & - Sustainability (adaptation to the nature, human development) \\
Remarkable landscapes, land and & - Endangered situation (variation tendency, stress factor) \\
water resources management fea- & Supplementary measures \\
tures & - Demonstration effect (participation, accessibility, promotion) \\
& - b. Guarantee measures (institution, policy, planning) \\
\hline
\end{tabular}

Although there are differences between GIAHS and China-NIAHS in the definition and selection criteria, both of them include tangible and intangible parts that could also be found in cultural and natural mixed heritages as well as in cultural landscapes. However, agricultural heritage systems are distinct from and more complex than conventional heritages (Min and Sun, 2009), as they are living, evolving systems of human communities in an intricate relationship with their environment, agricultural landscape, biophysical and wider social system. Human beings and their livelihood activities have continually adapted to the potentials and constraints of the environment and also shaped the landscape and the biological environment to different degrees. This has led to an accumulation of experiences over generations, an increasing range and depth of their knowledge systems and generally, but not necessarily, a complex and diverse range of livelihood activities, often closely integrated (Min et al., 2010).

By the end of 2015, there were a total of 62 China-NIAHS sites recognized by MOA, which included 11 GIAHS sites certified by FAO. Although they are located in different geographic regions (Figure 1), created by different ethnic groups, characterized by different types of agricultural production and maintained under different levels of economic development, all of these systems provide outstanding contributions to promoting food security, biodiversity, indigenous knowledge and cultural diversity for sustainable development at both local and national levels as complex, living and adaptive systems. Their comprehensiveness therefore determines that their conservation is also a complex, systematic "engineering" (Fuller and Min, 2013), which is different from and more complicated than that of conventional heritages and should be considered and performed in a holistic way (dela Cruz and Koohafkan, 2009).

Specifically, what should be conserved, in the conservation of agricultural heritage systems, includes both physical and biological components (i.e., local species and varieties, agricultural biodiversity, important ecosystem functions, ecological and cultural landscapes) and associated socio-cultural processes (i.e., cultural and value systems, knowledge and technology systems for agricultural production, bio-resources utilization, land and water resources management and environmental conservation).

${ }^{3}$ http://www.gov.cn/gzdt/2012-03/13/content_2090758.htm [accessed on 15 March, 2016] 


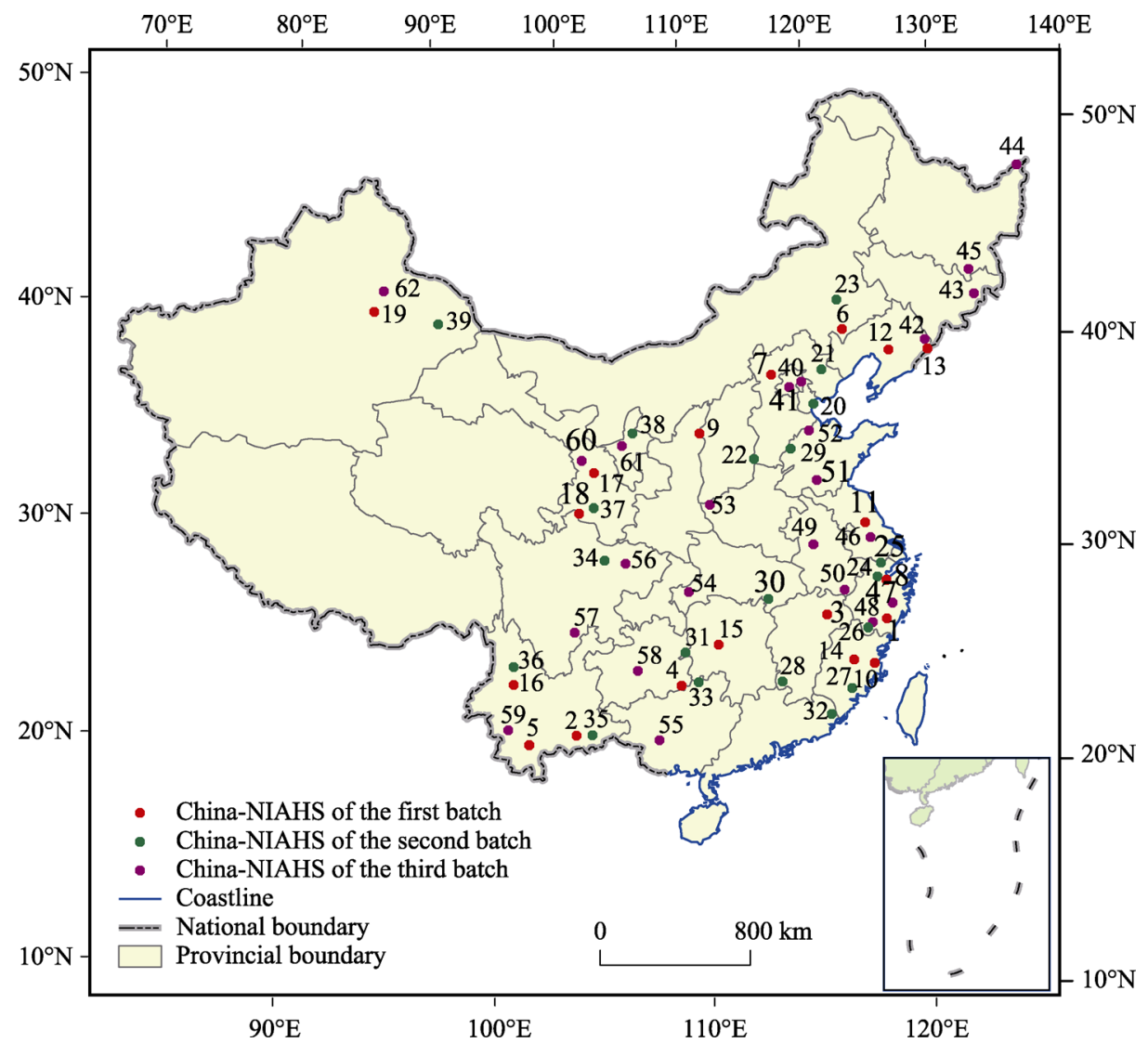

Figure 1 Distribution of GIAHS and China-NIAHS in China

Note: Refer to Appendix 1 for the names of agricultural heritage systems represented by numbers

\section{Who should conserve them?}

For centuries, it is farm communities that have developed these diverse and locally adapted agricultural heritage systems, managing them with ingenious practices that result in food security and agro-biodiversity conservation. Theoretically, farmers who continue with traditional agricultural production are supposed to be the owners as well as the protectors of agricultural heritage systems. However, given the endangered situation which some of the systems are facing, it is difficult to fulfill the purpose of the conservation by relying on farmers only. Besides, it is also unfair to impose the pressure of conserving the heritages shared by all humankind on farmers who are vulnerable members of society. Therefore, a multi-stakeholder process must be established for a more effective conservation of agricultural heritage systems (Min and Zhong, 2006).

The multi-stakeholders are identified as governments (central and local governments and their different sectors), multi-disciplinary scientists (ecologists, agronomists, economists, historians, planners, managers, etc.), communities and farmers, enterprises as well as social organizations (media, citizens, non-governmental organizations, etc.) and shall all participate in the conservation of agricultural heritage systems at different levels (Table 2).

In China, a multi-stakeholder process was established at the very beginning that can be 
traced back to the period of 2005 to 2008 when FAO/GEF-GIAHS -China Rice-Fish Culture project was under preparation (Min et al., 2009b). After ten years of trial and improvement, a "Five-in-One" multi-stakeholder process has been gradually established, which is led by governments, promoted by scientists and driven by enterprises with active participation of communities and farmers and cooperation from social organizations.

Both local and national governments are playing a leading role in the conservation of agricultural heritage systems in China by formulating conservation policies and planning, implementing standardized management and providing financial support (Zhao et al., 2012). For governments, one of the most important tasks is to incorporate the conservation and management of agricultural heritage systems into the general plan for local or national development and to combine their conservation with other development strategies (Cao, 2012; Zhang and Liu, 2014). It also should be noted that the conservation of agricultural heritage systems involves a variety of departments besides agriculture, such as forestry, animal husbandry, water conservation, environmental protection, culture, tourism, science and technology, education, etc. Therefore, how to coordinate different departments and make joint efforts to conserve agricultural heritage systems is another important task for governments (Zhang and Liu, 2014).

Table 2 Participation strategy of multi-stakeholders at different levels (dela Cruz and Koohafkan, 2009)

\begin{tabular}{|c|c|c|c|}
\hline Level & Stakeholder & Main task & Support needed \\
\hline National & $\begin{array}{l}\text { National government, } \\
\text { non-governmental } \\
\text { organizations (NGOs), } \\
\text { line ministries }\end{array}$ & $\begin{array}{l}\text { Develop/enhance national policies and } \\
\text { legislation and make resources available } \\
\text { to implement dynamic conservation and } \\
\text { mainstreaming of GIAHS in the national } \\
\text { program }\end{array}$ & $\begin{array}{l}\text { GIAHS concept and } \\
\text { strategic focus, politi- } \\
\text { cal support, technical } \\
\text { and financial resources }\end{array}$ \\
\hline $\begin{array}{l}\text { Meso-level } \\
\text { (regional/ } \\
\text { provincial/ } \\
\text { district) }\end{array}$ & $\begin{array}{l}\text { Province or district } \\
\text { government, NGOs, } \\
\text { businesses/ planning } \\
\text { unit }\end{array}$ & $\begin{array}{l}\text { - Institutional development and networking } \\
\text { Implement national policies: coordinate } \\
\text { involvement of practicing actors in dy- } \\
\text { namic conservation of GIAHS, organize } \\
\text { application of policies like payment for } \\
\text { biodiversity, water services, promote } \\
\text { cultural diversity }\end{array}$ & $\begin{array}{l}\text { Supporting national } \\
\text { policies and resources }\end{array}$ \\
\hline $\begin{array}{l}\text { Local } \\
\text { (community) }\end{array}$ & $\begin{array}{l}\text { Local farmers, local } \\
\text { government, local } \\
\text { businesses, academe }\end{array}$ & $\begin{array}{l}\text { - } \text { GIAHS dynamic conservation } \\
\text { - } \quad \text { Local innovation and knowledge sharing } \\
\text { - } \quad \text { alorization and develop pride in } \\
\text { tradition and culture } \\
\text { - } \quad \begin{array}{l}\text { Participate in decentralized governance } \\
\text { and natural resources management }\end{array} \\
\text { - Communicate needs to higher govern- } \\
\text { ance levels }\end{array}$ & $\begin{array}{l}\text { Capacity building, } \\
\text { local empowerment, } \\
\text { payment for environ- } \\
\text { mental services, } \\
\text { market access and } \\
\text { development }\end{array}$ \\
\hline Research & Academe & $\begin{array}{l}\text { - Link concepts and practice } \\
\text { - Develop operational systems (biodiver- } \\
\text { sity, socio-ecology, institutional devel- } \\
\text { opment) }\end{array}$ & $\begin{array}{l}\text { Global conceptual } \\
\text { clarity }\end{array}$ \\
\hline $\begin{array}{l}\text { Market/ } \\
\text { Trade }\end{array}$ & $\begin{array}{l}\text { Private sector and/or } \\
\text { line ministries in } \\
\text { trade, industry and/or } \\
\text { tourism }\end{array}$ & $\begin{array}{l}\text { - Link productivity, quality and payments, } \\
\text { niche products, eco-tourism, etc. }\end{array}$ & $\begin{array}{l}\text { Legal framework for } \\
\text { labeling of methods } \\
\text { and origins of } \\
\text { production etc. }\end{array}$ \\
\hline
\end{tabular}

Science and technology is also playing a very important part in the conservation of agricultural heritage systems. Experts from different disciplines like ecology, history, culture and economy have widely participated in the conservation of agricultural heritage systems by 
assessing their multiple values, analyzing and enhancing their sustainable mechanisms, assisting in the formulation of conservation and development planning, combining traditional knowledge with modern technologies and promoting scientific popularization (Min et al., 2010). The important role that enterprises are playing in the conservation of agricultural heritage systems is represented in developing products and markets, increasing capital investment and improving management abilities.

Communities and farmers are the "masters" of agricultural heritage systems, who are directly involved in the conservation of agricultural heritage systems (Geng et al., 2008). They are also the main bodies of cultural inheritance, agricultural production and market operation, therefore being the main beneficiaries of the achievements of the conservation. The new-style of farmers who combine traditional knowledge with modern technologies to enhance agricultural production and management are needed in the future. The awareness raising and active participation of the public will create a good social environment for the conservation of agricultural heritage systems. Both domestic and international experiences indicate that the participation of media and NGOs has brought about a critical boosting effect on heritage conservation (Min et al., 2010). In addition, citizens are also very important in the conservation of agricultural heritage systems, demonstrated by the adoption system and volunteer system implemented in Japan to promote heritage conservation (Zhang $\mathrm{C}$ et al., 2015).

\section{How should they be conserved?}

Agricultural heritage systems are described as living systems that are dynamic and adaptive, exhibiting strategic values of multi-functionality and sustainability (Min et al., 2011). Given these distinctive features, the conservation of agricultural heritage systems cannot be fulfilled by adopting conventional measures that were used on conventional heritages like ancient architecture (Min and Sun, 2009) which is basically static. Maintaining agricultural heritage systems in a static, unchanging way will to some extent result in more serious damage in the long run or in the maintenance of continuous poverty. Therefore, the conservation of agricultural heritage systems must be conducted in a dynamic way so that local farmers can benefit from the continuance of the traditional agricultural production while the heritage site can seek development under the premise of ecological functions being conserved and traditional culture being inherited (Koohafkan and dela Cruz, 2011).

As mentioned above, agricultural heritage systems provide important ecosystem services, such as water and soil conservation, micro-climate regulation, reduction in non-point pollution and biodiversity conservation. However, these important ecosystem services are public goods with externalities, which means that the residents cannot directly benefit from their conservation in an economically measurable way (Min et al., 2008). Therefore, a mechanism of payment for ecosystem services (PES) is needed to be used as an incentive to encourage the residents to continue practicing traditional agricultural production methods (Min et al., 2012). For instance, Liu et al. (2014) investigated the willingness of farmers to accept, under different conditions, reduced use of chemical pesticides and fertilizers in rice paddies. Combined with the value of ecosystem services, the dynamic PES standards are established that fluctuate with the price of agricultural products from the rice paddies, thus increasing the 
effectiveness of the PES mechanism implemented by the government. Zhang Y et al. (2015) established the PES standards for farmers who are in the transfer period of organic farming in rice terraces by calculating their economic loss during this period, therefore contributing to the adoption of environmentally friendly practices in the maintenance of agricultural heritage systems.

To realize dynamic conservation of agricultural heritage systems, a mechanism for preserving of cultural elements should also be established. Threatened by industrialization and urbanization, an abundance of traditional rules and regulations, customs and habits, as well as various art forms related to agriculture are faced with the risk of being lost without inheritance. Therefore, cultural elements in agricultural heritage systems should be treated the same as ecological ones like biodiversity, ecological functions and landscapes and be preserved with them as an entity in a dynamic way. For example, traditional villages in heritage sites should be renovated in the aspects of infrastructure, fireproofing and building structure so that they can meet the requirements for modern life in a better way (Zhang et al., 2011c; Yang et al., 2014) while maintaining the character, morphology and system of the old village. Modern information technologies should be utilized to publicize and promote traditional culture (Qiao, 2007) and combined with traditional connotations to make a balance between its development and its preservation (Lu and Wang, 2013).

Another important approach to enhance dynamic conservation is to establish a mechanism of eco-cultural industrial promotion that is derived from the multi-functionality of agricultural heritage systems. This mechanism is built upon agricultural production function and can be extended to other functions like agricultural product processing, biological resources utilization, cultural creativity and rural tourism (Min et al., 2012). It also seeks synergies between different functions. For instance, with the increasing requirements on food safety in modern society, more and more farmers in heritage sites have begun to utilize local biological resources and ecological conditions to produce high-quality agricultural products with cultural connotation, which are specialty products and which in turn promote the conservation of their agricultural heritage systems (He et al., 2009). Leisure agriculture and/or rural tourism is also considered an effective way to activate local residents to participate in the conservation of agricultural heritage systems while solving local employment and maintaining social stability (Sun, 2012; Li et al., 2015). For example, leisure agriculture and/or rural tourism developed on agricultural heritage systems has brought positive effects on the conservation of Rice-Fish Culture in Qingtian County, Zhejiang Province where labor shortage and land abandonment caused by urbanization has threatened the sustainability of the rice-fish system (Sun et al., 2006; Fuller et al., 2015). However, tourism is a coin with two sides. In the development of rural tourism, the characteristics of agricultural heritage systems must be fully considered (Min et al., 2007) and appropriate development modes must be chosen after tourism capacities and potentials are scientifically evaluated (Sun et al., 2011; Tian et al., 2015).

\section{Conclusions}

The conservation of agricultural heritage systems aims to promote the sustainable development of heritage sites, especially those ecologically fragile, economically undeveloped, but 
culturally rich areas, to improve the livelihood security and social welfare of local residents, and to provide references points for the development of modern agriculture in China. This includes lessons in resilience, adaptability and coping strategies, both physical and human, that offer strategic examples for modern farming systems to include. It does not mean that the conservation of agricultural heritage systems go against the development of modern practices as has been emphasized by dynamic conservation and adaptive management in GIAHS/NIAHS in China. This opposes both "destructive exploitation" without any planning or control as well as rigid, unchanging "frozen preservation". The conservation of agricultural heritage systems does not deviate from the improvement of the livelihood and well-being of local residents. On the contrary, it strives for providing diversified goods and services for local residents and increasing their living standards and quality of life on the basis of self-maintenance and self-development of agricultural heritage systems. The conservation of agricultural heritage systems is thus not opposed to the development of modern agriculture. Traditional agriculture and their combination with modern farming technologies points out the direction that modern agriculture should go in.

\section{References}

Altieri M A, Koohafkan P, 2007. Globally Important Ingenious Agricultural Heritage Systems (GIAHS): Extent, significance, and implications for development. http://www.fao.org/docrep/015/ap021e/ap021e.pdf. [accessed on 8 September 2007]

Bai Y, Min Q, Liu M et al., 2013. Resilience of the Hani rice terraces system to extreme drought. Journal of Food Agriculture \& Environment, 11(3/4): 2376-2382.

Berweck S, Koohafkan P, dela Cruz M J et al., 2013. Conceptual framework for economic evaluation of Globally Important Agricultural Heritage Systems (GIAHS): The case of Rice Fish Culture in China. Journal of Resources and Ecology, 4(3): 202-211.

Cao X, 2012. Agro-cultural heritage protection and new countryside construction. Journal of China Agricultural University (Social Sciences Edition), 29(3): 20-24. (in Chinese)

Dela Cruz M J and Koohafkan P, 2009. Globally Important Agricultural Heritage Systems: A shared vision of agricultural, ecological and traditional societal sustainability. Resources Science, 31(6): 905-913.

Duan H, Shao W, Wang S et al., 2004. Study on the genetic diversity of peculiar tea germplasm resource in Yunnan by RAPD. Journal of Yunnan Agricultural University, 19(3): 246-254. (in Chinese)

Fuller A M, Min Q, Jiao W et al., 2015. Globally Important Agricultural Heritage Systems (GIAHS) of China: The challenge of complexity in research. Ecosystem Health and Sustainability, 1(2): 6. http://dx.doi.org/10.1890/ EHS14-0007.1.

Fuller T, Min Q, 2013. Understanding agricultural heritage sites and complex adaptive systems: The challenge of complexity. Journal of Resources and Ecology, 4(3): 195-201.

Geng Y, Min Q, Cheng S et al., 2008. Discussion on multi-stakeholders collaborative mechanism for GIAHS conservation: Taking "traditional rice-fish agriculture" in Qingtian as an example. Ancient and Modern Agriculture, (1): 109-117. (in Chinese)

He L, Min Q, Zhang D et al., 2009. Study on agricultural development mode in traditional agricultural areas: A case study of Congjiang county of Guizhou Province. Resources Science, 31(6): 956-961. (in Chinese)

He L, Min Q, Zhang D et al., 2010. Evaluation models for multifunctionality of agriculture and their applications: A case study on Qingtian County in Zhejiang Province, China. Resources Science, 32(6): 1057-1064. (in Chinese)

He X, Sun Y, Gao D et al., 2011. Comparison of agronomic traits between rice landraces and modern varieties at different altitude in paddy field of Yuanyang Terrace, Yunnan Province. Journal of Resource and Ecology, 2(1): 46-50.

Jiao W, Min Q, Cheng S et al., 2009. Ecological capacity of a traditional agricultural area based on ecological footprint: A case study of Qingtian County, Zhejiang Province. Resources Science, 2009, 31(1): 63-68. (in 
Chinese)

Jiao W, Min Q, Cheng S et al., 2011. The Emergy-based Ecological Footprint (EEF) of traditional agricultural areas in China: The case study of Congjiang County, Guizhou Province. Journal of Resources and Ecology, 2(1): 289-299.

Jiao Y, Li X, Liang L et al., 2012. Indigenous ecological knowledge and natural resource management in the cultural landscape of China's Hani Terraces. Ecological Research, 27: 247-263.

Koohafkan P and dela Cruz M J, 2011. Conservation and adaptive management of Globally Important Agricultural Heritage Systems (GIAHS). Journal of Resources and Ecology, 2(1): 22-28.

Koohafkan P, 2009. Conservation and adaptive management of Globally Important Agricultural Heritage Systems (GIAHS). Resources Science, 31 (1): 4-9.

Lei Q, Zhang W, Sun J et al., 2013. Traditional management and utilization of glutinous rice genetic resources in southeast Guizhou. Plant Diversity and Resources, 35(2): 195-201. (in Chinese)

Li W, Liu M, Min Q, 2012. Agricultural heritage conservation: New opportunity for developing eco-agriculture. Chinese Journal of Eco-Agriculture, 20(6): 663-667. (in Chinese)

Li Z, Zou H, Yi Q et al., 2015. The agricultural cultural heritage tourism resources potential evaluation to terraces. Economic Geography, 35(6): 198-201. (in Chinese)

Liu M, Xiong Y, Yuan Z et al., 2014. Standards of ecological compensation for traditional eco-agriculture: Taking rice-fish system in Hani terrace as an example. Journal of Mountain Science, 11(4): 1049-1059.

Liu S, Min Q, Xu Y et al., 2011. Role of traditional knowledge in forest resources conservation in ethnic areas: A case study on Xiaohuang Village in Congjiang County, Guizhou Province. Resources Science, 33(6): 1046-1052. (in Chinese)

Liu W, Min Q, Bai Y et al., 2014. Impact of the GIAHS designation to local development and countermeasures. World Agriculture, (6): 89-93. (in Chinese)

Long Z, 2011. The ecological and ethical implications of the Miao people's common law in Qiandongnan prefecture of Guizhou Province. Journal of Guizhou Ethnic Institute (Philosophy and Social Science Edition), (1): 110-114. (in Chinese)

Lu Y, Wang S, 2013. The history and protection and inheritance of Xinghua raised field. Journal of China Agricultural University (Social Sciences Edition), 30(4): 141-148. (in Chinese)

Min Q, He L, Sun Y et al., 2012. On the value, conservation and sustainable development of GIAHS pilot sites in China. Chinese Journal of Eco-Agriculture, 20(6): 668-673. (in Chinese)

Min Q, He L, Zhang D, 2011. Agricultural heritage research in China: Progresses and perspectives. Journal of Resources and Ecology, 2 (1): 15-21.

Min Q, Jiao W, Sun Y et al., 2008. Ecosystem services and eco-compensation of traditional agricultural systems: Taking rice-fish culture as an example. In: Min Q (ed.). Agricultural Heritage Systems and Their Dynamic Conservation. Beijing: China Environmental Science Press, 299-310. (in Chinese)

Min Q, Li W, Yang G, 2009a. Rice-fish culture in China. In: Min Q ed. Dynamic Conservation and Adaptive Management of China's GIAHS: Theories and Practices (I). Beijing: China Environmental Science Press, 37-88.

Min Q, Sun Y, 2009. The concept, characteristics and conservation requirements of agro-cultural heritage. Resources Science, 31(6): 914-918. (in Chinese)

Min Q, Sun Y, Cheng S et al., 2007. Primary study on the features and development of GIAHS's tourism resources. Economic Geography, 27(5): 856-859. (in Chinese)

Min Q, Sun Y, Shi Y, 2010. GIAHS project and its implementation in China. Journal of Resources and Ecology, 1(1): 94-96.

Min Q, Sun Y, van Schoubroeck F et al., 2009b. The GIAHS-rice-fish culture: China project framework. Resources Science, 31(1): 10-20.

Min Q, Zhong Q, 2006. The Multi-stakeholder Processes in the Conservation of Agricultural Heritage Systems. Beijing: China Environment Science Press. (in Chinese)

Qiao X, 2007. Flow to inherit the music culture in songs of Dong Ethnic Group. Journal of Northeast Normal University (Philosophy and Social Sciences), (4): 109-114. (in Chinese)

Rao B, Zhou C, Wang J et al., 2009. Research on the rational allocation of water resources in Hani terrace irrigation area. Journal of Water Resources and Water Engineering, 20(6): 38-41. (in Chinese)

Ren H, Min Q, Wang W et al., 2014. Concentration of Aero-Anion and its influence factors in different habitats of Gushan Tea Garden, Fuzhou. Urban Environment \& Urban Ecology, 27(1): 1-6. (in Chinese) 
Ren W, Cao C, Wang J, 2008. Economic valuation of gas regulation as a service by rice-duck-fish complex ecosystem. Ecological Economy, (4): 266-272.

Sun X, Min Q, Bai Y et al., 2014. Analyzing environmental stress counter-measures in agricultural heritage sites in China. Journal of Resources and Ecology, 5(4): 328-334.

Sun Y, 2012. Research review on agricultural heritage systems and its tourism development. Journal of Landscape Research, 4(6): 54-58.

Sun Y, Min Q, Cheng S et al., 2006. Relationship between tourism resources development and regional social and economic development in agricultural heritage site: Taking "Traditional Rice-Fish Agriculture" of Qingtian County as an example. Resources Science, 28(4): 138-144. (in Chinese)

Sun Y, Min Q, Cheng S, 2008. Value of the GIAHS-China traditional rice-fish system. Chinese Journal of Eco-Agriculture, 16(4): 991-994. (in Chinese)

Sun Y, Min Q, Cheng S et al., 2011. The community potential for tourism development in agricultural heritage sites: A case study of Qingtian County. Geographical Research, 30(7): 1341-1350.

Sun Y, Zhou H, Zhang L et al., 2012. Adapting to droughts in Yuanyang Terrace of SW China: Insight from disaster risk reduction. Mitigation and Adaptation Strategies for Global Change. doi: 10.1007/s11027-012-9386- 2.

Tian M, Min Q, Lun F et al., 2015. Evaluation of tourism water capacity in agricultural heritage sites. Sustainability, 7(11): 15548-15569.

Xia Q, Shen M, 2014. Analysis on reasons for red rice flourishing and its features from Yuanyang terrace: A case study of moon valley. Journal of Anhui Agricultural Sciences, (30): 10826-10828. (in Chinese)

Xie J, Hu L, Tang J et al., 2011a. Ecological mechanisms underlying the sustainability of the agricultural heritage rice-fish coculture system. PNAS, 108(50): E1381-E1387.

Xie J, Liu L, Chen X et al., 2009. Control of diseases, pests and weeds in traditional rice-fish ecosystem in Zhejiang, China. Bulletin of Science and Technology, 25(6): 801-805.

Xie J, Wu X, Tang J et al., 2011b. Conservation of traditional rice varieties in a Globally Important Agricultural Heritage System (GIAHS): Rice-fish co-culture. Agricultural Sciences in China, 10(5): 754-761.

Xu H, Wang Q, Bai J et al., 2010. Changes of phosphate and ammonium nitrogen in irrigated waters of Hani terrace wetlands along the elevation gradients. Procedia Environmental Sciences, (2): 1368-1373.

Xue D, 2011. The categories and benefit-sharing of traditional knowledge associated with biodiversity. Journal of Resources and Ecology, 2(1): 29-33.

Yang G, Wang B, Bai Y, 2014. Approaches to dynamic protection on traditional agriculture with ancient torreya grandis in Kuaiji Mountain. Hunan Agricultural Sciences, (22): 59-61. (in Chinese)

Yang H, Lv Y, Min Q et al., 2009. Energy comparison of rice-fish agriculture and rice monocropping. Resources Research, 31(1): 48-55. (in Chinese)

Yuan Z, Lun F, He L et al., 2014. Exploring the state of retention of Traditional Ecological Knowledge (TEK) in a Hani rice terrace village, Southwest China. Sustainability, 6: 4497-4513.

Yuan Z, Min Q, Cheng S, 2013. The smallholder economy for the Hani rice terraces sustaining millennium. Journal of China Agricultural University, 30(4): 133-140. (in Chinese)

Zhang C, Chen L, Zhang Y, 2015. Japanese agricultural heritage system conservation: Multi-stakeholder mechanism and its policy enlightenment. World Agriculture, (12): 108-111. (in Chinese)

Zhang C, Liu M, 2014. Challenges and countermeasures for the sustainable development of Nationally Important Agricultural Heritage Systems in China. Journal of Resources and Ecology, 5(4): 390-394.

Zhang D, Cheng S, Yang H et al., 2011a. Ecological control effects on pest, pathogen and weed of multiple Species coexistence in paddy fields in traditional agricultural regions. Resources Science, 33 (6): 1032-1037. (in Chinese)

Zhang D, Min Q, Liu M et al., 2011b. Ecosystem service tradeoff between traditional and modern agriculture: A case study in Congjiang County, Guizhou Province, China. Frontiers of Environmental Science \& Engineering, 6(5): 743-752.

Zhang K, Min Q, Xu X, 2011c. Agricultural connotation and conservation measures of traditional Dong villages: A case study on Xiaohuang Village, Congaing County, Guizhou Province. Resources Science, 33(6): 1038-1045. (in Chinese)

Zhang L, Li F, Cui H, 2014a. Role of traditional agricultural ecosystem on prevention-and-cure agricultural non-point source pollution: A case study of rice-fish-duck symbiotic model in Congjiang County, Guizhou Province. Ecological Economy, 30(5): 131-134.

Zhang Y, Liu M, Min Q et al., 2014b. Environmental adaptability and service functions of Chinese jujube forest 
ecosystem in Jiaxian County, Shaanxi Province. Arid Zone Research, 31(3): 416-423. (in Chinese)

Zhang Y, Liu M, Min Q et al., 2015. Calculation of price compensation of agriculture products in the period of organic conversion in agricultural heritage sites: Taking paddy rice of Hani terrace in Honghe County of Yunnan Province as an example. Journal of Natural Resources, 30(3): 374-383. (in Chinese)

Zhao L, Xu W, Sun Y et al., 2012. On the conservation of China's agricultural heritage systems. Chinese Journal of Eco-Agriculture, 20(6): 688-692. (in Chinese)

Zhao W, Min Q, Cui M, 2011. Wild rice resources in the Lancang watershed and its significance in agricultural heritage protection. Resources Science, 33(6): 1066-1071. (in Chinese)

Zhu G, Lu Y, Li Q, 2015. Inheritance and development of traditional ecological farming system in Lake Taihu area under background of modernization: From perspective of agricultural heritage. Journal of Nanjing Agricultural University (Social Science Edition), 15(2): 109-116, 128. (in Chinese)

Zhu Y, Chen H, Fan J et al., 2000. Genetic diversity and disease control in rice. Nature, 406: 718-722.

Zong L, Jiao Y, Hua H et al., 2014. Vertical changes of soil moisture and water holding capacity of Hani terraces landscape in water conservation forest region. Bulletin of Soil and Water Conservation, 34(4): 59-64. (in Chinese)

\section{Appendix}

Appendix 1: The list of GIAHS and China-NIAHS in China

\begin{tabular}{|c|c|c|c|}
\hline No. & Batch & $\begin{array}{c}\text { Designation Year } \\
\text { (China-NIAHS/ } \\
\text { GIAHS) }\end{array}$ & Name \\
\hline 1 & 1 & $2013 / 2005$ & Qingtian Rice-Fish Culture, Zhejiang Province \\
\hline 2 & 1 & $2013 / 2010$ & Honghe Hani Rice Terraces, Yunnan Province \\
\hline 3 & 1 & $2013 / 2010$ & Wannian Traditional Rice Culture, Jiangxi Province \\
\hline 4 & 1 & $2013 / 2011$ & Congjiang Dong's Rice-Fish-Duck System, Guizhou Province \\
\hline 5 & 1 & $2013 / 2012$ & Pu'er Traditional Tea Agrosystem, Yunnan Province \\
\hline 6 & 1 & $2013 / 2012$ & Aohan Dryland Farming System, Inner Mongolia Autonomous Region \\
\hline 7 & 1 & $2013 / 2013$ & Xuanhua Traditional Vineyards, Hebei Province \\
\hline 8 & 1 & $2013 / 2013$ & Shaoxing Kuaijishan Ancient Chinese Torreya, Zhejiang Province \\
\hline 9 & 1 & $2013 / 2014$ & Jiaxian Traditional Chinese Date Gardens, Shaanxi Province \\
\hline 10 & 1 & $2013 / 2014$ & Fuzhou Jasmine and Tea Culture System, Fujian Province \\
\hline 11 & 1 & $2013 / 2014$ & Xinghua Duotian Agrosystem, Jiangsu Province \\
\hline 12 & 1 & 2013 & Anshan Nanguo Pear Planting System, Liaoning Province \\
\hline 13 & 1 & 2013 & Kuandian Traditional Shizhu Ginseng Cultivation System, Liaoning Province \\
\hline 14 & 1 & 2013 & Youxi Lianhe Rice Terraces, Fujian Province \\
\hline 15 & 1 & 2013 & Xinhua Ziquejie Rice Terraces, Hunan Province \\
\hline 16 & 1 & 2013 & $\begin{array}{l}\text { Yangbi Juglans Sigillata Dode and Crops Composite System, Yunnan } \\
\text { Province }\end{array}$ \\
\hline 17 & 1 & 2013 & Shichuan Traditional Pear Gardens, Gansu Province \\
\hline 18 & 1 & 2013 & Zhagana Agro-Sylvo-Pastoral Compound System, Gansu Province \\
\hline 19 & 1 & 2013 & Turfan Karez Agrosystem, Xinjiang Autonomous Region \\
\hline 20 & 2 & 2014 & Cuizhuang Ancient Winter Jujube Gardens, Tianjin \\
\hline 21 & 2 & 2014 & Kuancheng Traditional Chinese Chestnut Planting System, Hebei Province \\
\hline 22 & 2 & 2014 & Shexian Dryland Terraces, Hebei Province \\
\hline
\end{tabular}


(Continued)

\begin{tabular}{|c|c|c|c|}
\hline No. & Batch & $\begin{array}{c}\text { Designation Year } \\
\text { (China-NIAHS/ } \\
\text { GIAHS) }\end{array}$ & Name \\
\hline 23 & 2 & 2014 & Arhorchin Grassland Nomadic System, Inner Mongolia Autonomous Region \\
\hline 24 & 2 & 2014 & Hangzhou West Lake Longjing Tea Culture System, Zhejiang Province \\
\hline 25 & 2 & 2014 & Huzhou Mulberry-Dyke-Fish-Pond System, Zhejiang Province \\
\hline 26 & 2 & 2014 & Qingyuan Mushroom Culture System, Zhejiang Province \\
\hline 27 & 2 & 2014 & Anxi Tieguanyin Tea Culture System, Fujian Province \\
\hline 28 & 2 & 2014 & Chongyi Hakka Rice Terraces, Jiangxi Province \\
\hline 29 & 2 & 2014 & $\begin{array}{l}\text { Xiajin Ancient Mulberry Groves in Old Yellow River Course, } \\
\text { Shandong Province }\end{array}$ \\
\hline 30 & 2 & 2014 & Yangloudong Brick Tea Culture System, Hubei Province \\
\hline 31 & 2 & 2014 & Xinhuang Dong-Treasured-Red-Rice Culture System, Hunan Province \\
\hline 32 & 2 & 2014 & Chao'an Camellia sinens Tea Culture System, Guangdong Province \\
\hline 33 & 2 & 2014 & Lonhsheng Longji Rice Terraces, Guangxi Zhuang Autonomous Region \\
\hline 34 & 2 & 2014 & Jiangyou Traditional Magnolia Flower Planting System, Sichuan Province \\
\hline 35 & 2 & 2014 & Guangnan Babao Rice Culture System, Yunnan Province \\
\hline 36 & 2 & 2014 & Jianchuan Rice-Wheat Rotation Farming System, Yunnan Province \\
\hline 37 & 2 & 2014 & Minxian Angelica Sinensis Cropping System, Gansu Province \\
\hline 38 & 2 & 2014 & Lingwu Long Jujube Cropping System, Ningxia Hui Autonomous Region \\
\hline 39 & 2 & 2014 & Hami Melon Cultivation System, Xinjiang Uygur Autonomous Region \\
\hline 40 & 3 & 2015 & Pinggu Sizuolou Juglans hopeiensis Planting System, Beijing \\
\hline 41 & 3 & 2015 & Jing-Xi-Rice Culture System, Beijing \\
\hline 42 & 3 & 2015 & Huanren Jingzu Rice Culture System, Liaoning Province \\
\hline 43 & 3 & 2015 & Yanbian Apple Pear Planting System, Jilin Province \\
\hline 44 & 3 & 2015 & Fuyuan Fish Culture System of Hezhe Nationality, Heilongjiang Province \\
\hline 45 & 3 & 2015 & Ning'an Xiangshui Rice Culture System, Heilongjiang Province \\
\hline 46 & 3 & 2015 & Taixing Gingko Planting System, Jiangsu Province \\
\hline 47 & 3 & 2015 & Xianju Waxberry Planting System, Zhejiang Province \\
\hline 48 & 3 & 2015 & Yunhe Rice Terraces, Zhejiang Province \\
\hline 49 & 3 & 2015 & $\begin{array}{l}\text { Shouxian Quebei Irrigation Project (Anfeng Reservoir) and Irrigated Farming } \\
\text { System, Anhui Province }\end{array}$ \\
\hline 50 & 3 & 2015 & Xiuning Fishery System with Flowing Mountain Spring, Anhui Province \\
\hline 51 & 3 & 2015 & Zaozhuang Ancient Jujube Forests, Shandong Province \\
\hline 52 & 3 & 2015 & Laoling Jujube-crop Eco-farming System, Shandong Province \\
\hline 53 & 3 & 2015 & Lingbao Ancient Valley-and-Plain Jujube Forest, Henan Province \\
\hline 54 & 3 & 2015 & Enshi Gyokuro Tea Culture System, Hubei Province \\
\hline 55 & 3 & 2015 & $\begin{array}{l}\text { Longan "Na" Rice Culture System of Zhuang Nationality, } \\
\text { Guangxi Zhuang Autonomous Region }\end{array}$ \\
\hline 56 & 3 & 2015 & Cangxi Snow Pear Planting System, Sichuan Province \\
\hline 57 & 3 & 2015 & Meigu Tartary Buckwheat Farming System, Sichuan Province \\
\hline 58 & 3 & 2015 & Huaxi Ancient Tea and Culture System, Guizhou Province \\
\hline 59 & 3 & 2015 & Shuangjiang Mengku Ancient Tea and Culture System, Yunnan Province \\
\hline 60 & 3 & 2015 & Yongdeng Kushui Rose Farming System, Gansu Province \\
\hline 61 & 3 & 2015 & $\begin{array}{l}\text { Zhongning Chinese Wolfberry Cultivation System, Ningxia Hui Autonomous } \\
\text { Region }\end{array}$ \\
\hline 62 & 3 & 2015 & Qitai Dryland Farming Landscape, Xinjiang Uygur Autonomous Region \\
\hline
\end{tabular}

